\title{
Como fazer pesquisa com crianças em tempos de pandemia? Perguntemos a elas
}

Luciana Hartmann

Submetido em: 07/10/2020

Aprovado em: 30/10/2020

DOI: $10.5965 / 23580925242020029$

1 Doutora em Antropologia Social pela Universidade Federal de Santa Catarina (UFSC). Professora do Departamento de Artes Cênicas da Universidade de Brasília (UnB). E-mail: luhartm71@gmail.com 


\section{RESUMO}

Este artigo é sobre perguntas: sobre como e o que perguntar às crianças, em uma situação de pandemia, e sobre as respostas-perguntas que elas deram aos nossos questionamentos. Descrevo inicialmente o processo de elaboração compartilhada, entre adultos e crianças, de um questionário direcionado a crianças de 06 a 12 anos de idade que vivenciaram o isolamento social decorrente da pandemia de Covid-19. No processo de análise das respostas constatei que algumas foram dadas em forma de pergunta. A pergunta aparece como desafio, como dúvida, como reflexão das crianças em relação às categorias, demandas e percepções que nós, adultos-pesquisadores frequentemente projetamos em nossas pesquisas. Problematizar a relação criança-adulto na realização de pesquisas na confluência entre o teatro e a antropologia e valorizar o papel da pergunta neste processo é o objetivo deste artigo.

Palavras-chave: estudos da infância, Covid-19, metodologias de pesquisa com crianças, pedagogia do teatro, marcadores sociais da diferença.

\section{ABSTRACT}

This article is about questions: how and what to ask children in a pandemic situation, and about the questions-answers they gave to our questions. I describe, initially, the process of development shared between adults and children of a questionnaire aimed at children from 6 to 12 years who experienced the social isolation resulting from the Covid-19 pandemic. Next, I analyze some of the answers that were given in the format of questions. These questions emerge as a challenge, $a$ doubt, a reflection of the children about the adult categories, demands and perceptions. The objective of this article is to 
problematize the child-adult relationship at the confluence of theater and anthropology research and to value the role of the question in this process.

Keywords: childhood studies, Covid-19, children's methodologies of research, theatre pedagogy, social markers of difference.

Por que as mães ficam nervosas?

Quando o corona vai embora?

Quem mandou o corona?

Athos, 7 anos

Quando comecei a escrever este artigo, a primeira coisa que fiz foi escolher uma das respostas que as crianças haviam dado ao questionário que propus, em junho de 2020, visando conhecer suas vivências e percepções durante o período de isolamento social decorrente da pandemia de Covid-19. Venho estudando a produção narrativa de crianças e adultos há mais de 20 anos e acredito que nada mais coerente do que evidenciar as vozes dos interlocutores em todos os meus escritos. São elas que motivam minhas investigações, que dão o tom de minha escrita e que inspiram minhas reflexões. Neste caso não foi diferente, mas o curioso é que ao longo da redação do texto (processo que para mim é, ambiguamente, técnico e mágico), as respostas revelaram não somente sobre O QUE pensam as crianças, mas também sobre COMO elas se relacionam com 0 mundo ao redor e refletem sobre suas experiências. Fui percebendo ao longo da escrita que, em muitos casos, as crianças responderam com perguntas.

Aqui há uma clara combinação entre o que os dados revelam e os meus referenciais teóricos. Foi a trajetória entre a antropologia e o teatro, no campo dos estudos da performance, e mais especificamente, com as "performances narrativas" (HARTMANN, 2014), que impulsionou meu olhar sobre o que passarei 
a chamar de "respostas-perguntas" das crianças.

As perguntas fazem parte de nossas performances cotidianas, de nossos processos de aprendizagem, desde a mais tenra idade: "Aparentemente perguntar é uma ação potencialmente presente na vida de todo ser humano. Aprendemos a aprender a partir da curiosidade, da pergunta." (RUBINSTEIN, 2019, p. 321). Seguindo essa lógica, esse será um artigo sobre perguntas, literalmente: sobre como e o que perguntar às crianças, em uma situação de pandemia, e sobre as respostas-perguntas que elas deram aos nossos questionamentos.

Começo contando um pouco sobre o contexto que impulsionou a criação do questionário.

Era a primeira semana de março de 2020 e finalmente eu estava entrando em uma escola pública de Lisboa na categoria de "pesquisadora". Desde dezembro de 2019, quando chegara a Portugal para realizar minha pesquisa de pós-doutorado sobre narrativas de crianças imigrantes, estava fazendo contatos e procurando contornar o lento, tortuoso e intrincado caminho da burocracia estatal. Como já havia acontecido quando estive pesquisando o mesmo tema na França (HARTMANN, 2017, 2018), foi uma professora disposta a desenvolver uma parceria que me abriu as portas de sua sala de aula. O que não poderíamos imaginar, no entanto, era que depois daquela manhã de conversas, brincadeiras, cantorias e histórias com a turma de $1^{\circ}$. Ano da Escola Básica do Castelo, todas as escolas portuguesas fossem fechadas e que o ano letivo de 2019-2010 fosse definitivamente encerrado sem aulas presenciais devido à pandemia de Covid-19. Depois de algumas semanas de prostração, estupefação e reflexão (não necessariamente nessa ordem), me perguntei: como fazer pesquisa com crianças em tempos de pandemia? $\mathrm{Na}$ falta de uma resposta, em um momento que eu e grande parte das pesquisadoras nos perguntávamos como (re)agir em relação à crise instaurada pela pandemia, acabei encontrando uma alternativa: vou começar perguntando às próprias crianças. E foi com a ajuda delas que elaborei o questionário "As crianças e a Covid-19: experiências, imagens, histórias", direcionado a pequenos cidadãos confinados de 06 a 12 anos de idade. 
Sem abandonar a perspectiva de retomar a pesquisa específica com as crianças imigrantes, encontrei no questionário uma alternativa para me manter em diálogo com as crianças, explorando com elas estratégias possíveis de investigação em tempos de pandemia. Algum tempo depois de tomar essa decisão me deparei com a espirituosa conferência de Daniel Miller, "Notas sobre a pandemia: Como conduzir uma etnografia durante o isolamento social", que me inspira a acreditar que essa experiência desafiante (eu nunca havia utilizado um questionário) possa render um bom debate. Segundo ele: "no final das contas, muitas vezes são as coisas que as pessoas nunca pretenderam fazer, esperavam fazer ou realmente tiveram que fazer por padrão que acabaram por figurar entre as descobertas mais interessantes de seus projetos." (MILLER, 2020, s/p).

Em seu formato final, o questionário contou com 54 perguntas, com diferentes possibilidades de respostas, entre múltipla escolha, caixa de seleção e respostas discursivas. Também foram abertas opções para as crianças enviarem fotos, vídeos e áudios. Todas as respostas foram anônimas e contaram com o consentimento do/a adulto/a responsável e da criança. Até o momento o questionário conta com 118 respondentes, dentre os quais 114 são crianças brasileiras, das cinco regiões do país, 3 portuguesas e 1 francesa.

Ao longo do texto, que propõe uma análise apenas parcial do questionário, farei um debate não somente acerca de algumas das respostas das crianças, mas sobretudo do processo, partilhado com elas, de escolha e organização das perguntas que o comporiam. Ou seja, eu, alguns adultos e algumas crianças decidimos juntos O QUE e COMO perguntar sobre a pandemia de Covid-19. Essas reflexões se inserem em uma perspectiva ética e metodológica das pesquisas que venho realizando há alguns anos, nas quais as crianças são consideradas como "co-pesquisadoras", partícipes não apenas no processo de produção de dados, mas também de planejamento e, por que não, de análise dos mesmos.

Essa abordagem de pesquisa partilhada com as crianças vem sendo desenvolvida e aprimorada na prática, desde 2013, quando comecei um projeto intitulado "Pequenos narradores", 
com estudantes de três turmas de quinto ano de uma escola pública do Distrito Federal. O objetivo do projeto era a escuta e produção de narrativas, sobre qualquer tema, por parte das crianças, com posterior elaboração de um livro artesanal, por cada uma das turmas. Eu levava algumas propostas de jogos, atividades e histórias para as crianças e logo percebi que elas, por sua vez, não apenas alteravam ou sugeriam novas atividades como também questionavam a própria metodologia de trabalho. Por exemplo: nos encontros eu propunha uma partilha de narrativas numa grande roda, mas nem todas as crianças se aventuravam a contar suas histórias no coletivo. Em um dado momento algumas vieram me explicar que havia colegas tímidos ou "com histórias muito tristes". Então elas próprias propuseram uma solução: por que não fazíamos sessões privadas, em uma pequena sala, nas quais apenas uma ou duas crianças pudessem contar suas histórias? Isso possibilitou que todas fossem escutadas, respeitando suas subjetividades. Armagnague e Rigoni (2016) também defendem que nas pesquisas com crianças devemos tomar um cuidado teórico e metodológico que considere, por um lado, a questão central da subjetividade da criança e, de outro, valorize sua capacidade de mobilização política e de análise do mundo social.

Em minhas investigações, assim, passei a prestar especial atenção às contribuições das crianças e suas estratégias de abordagem passaram a contribuir no próprio encaminhamento do trabalho. A partir de então, eu e outras pesquisadoras sob minha orientação passamos a radicalizar a proposta de escuta e ação compartilhada com as crianças, assumindo a participação delas, de fato, como co-pesquisadoras.

Desde o início desse processo de pesquisa com crianças fui bastante inspirada por Priscila Alderson, que no artigo As crianças como pesquisadoras: os efeitos dos direitos de participação sobre a metodologia de pesquisa faz uma revisão da literatura a partir da qual elege três abordagens: as diferentes fases da pesquisa nas quais as crianças podem se engajar, os distintos níveis de participação delas e quais métodos permitem incrementar o envolvimento devidamente informado das crianças 
em pesquisas. Em todas essas abordagens ela defende que as crianças sejam reconhecidas como sujeitos de pesquisa capazes de refletir sobre suas próprias vidas (ALDERSON, 2005, p. 422). Também me apoio em Soares, Sarmento e Tomás, que com uma perspectiva semelhante sustentam que:

\begin{abstract}
A Sociologia da Infância, ao assumir que as crianças são actores sociais plenos, competentes na formulação de interpretações sobre os seus mundos de vida e reveladores das realidades sociais onde se inserem, considera as metodologias participativas com crianças como um recurso metodológico importante, no sentido de atribuir aos mais jovens o estatuto de sujeitos de conhecimento, e não de simples objecto, instituindo formas colaborativas de construção do conhecimento nas ciências sociais que se articulam com modos de produção do saber empenhados na transformação social e na extensão dos direitos sociais. (SOARES; SARMENTO; TOMÁS, 2005, p. 54)
\end{abstract}

Segundo os autores, no entanto, essas formas colaborativas apresentam algumas dificuldades epistemológicas e desafios metodológicos aos/às pesquisadores/as das infâncias, que devem ser criativos na definição de ferramentas metodológicas adequadas e também estar dispostos a repensar sua própria identidade, descentrando-se do tradicional papel de gestores de todo o processo, para conceber a co-gestão do trabalho investigativo com as crianças. (SOARES; SARMENTO; TOMÁS, 2005, p. 55)

Acredito que aqui aparecem algumas chaves para pensar a pesquisa com crianças: disponibilidade do/a pesquisador/a para abandonar o controle central da pesquisa, constante exercício de criatividade, em diálogo com a própria criança, e consciência da instabilidade dos processos (cada contexto é um contexto, cada dia é um dia, cada criança é uma criança). Para além dessas, diria que há outra fundamental: ao invés de respostas fechadas, possivelmente as crianças nos instiguem e desafiem com outras perguntas. O que quero defender aqui é que esse comportamento característico da infância pode enriquecer o 
modus operandi adulto de fazer pesquisa. Se adotarmos realmente as crianças como parceiras, poderemos verificar, como sugere Alderson, que "as crianças são provavelmente mais interessadas que os adultos por cada estágio da pesquisa. Muitas delas estão acostumadas a questionar, investigar e aceitar resultados inesperados, mudar de idéia, e assumir que seus conhecimentos são incompletos e provisórios." (ALDERSON, 2005, p. 426) Vejamos então como se deu, na prática, a partilha da elaboração do questionário "As crianças e a Covid-19" com as crianças.

\section{COMO REALIZAR PESQUISA EM COLABORA- ÇÃO COM AS CRIANÇAS?}

Para desenvolver o questionário contei inicialmente com a parceria de minha filha menor, Nina, de 11 anos. Afetada diretamente pelas medidas de isolamento social decorrentes da pandemia, Nina também ficou longe da escola e dos amigos e acompanhamos juntas as dificuldades e a dedicação dos professores portugueses na rápida (posto que fortemente imposta) adaptação ao ensino remoto. Baseadas em outros questionários que tematizavam a pandemia, porém direcionados para adultos, e percebendo a carência de estudos específicos sobre a vivência das crianças neste contexto, eu e ela começamos a elaborar algumas perguntas. Para começar, pensamos em dois blocos de questões: um que intitulamos "Quem sou e como eu vivo" e outro "O Coronavírus e as mudanças na rotina". Esses títulos acabaram desaparecendo na formatação final do questionário, mas foram importantes para definirmos um âmbito de perguntas que possibilitassem contextualizar as crianças e outro, na sequência, que se dedicasse especificamente aos impactos da pandemia na vida delas.

Em "Quem sou e como vivo", a ideia era que pudéssemos ter alguns dados básicos que depois permitissem compreender o contexto identitário e socioeconômico da criança (idade, gênero, cor, classe social). Já em “O Coronavírus e as mudanças na rotina" pensamos em perguntas sobre a compreensão do vírus, 
a experiência do isolamento social e a questão do fechamento das escolas, entre outras.

Depois de elaborarmos cerca de 40 perguntas iniciais, enviei o questionário a colegas e alunas/os para que pedissem a opinião de seus filhos e filhas - se eles/elas tinham críticas, acréscimos ou sugestões de novas perguntas.

Quero dedicar especial atenção à essa fase do processo, pois nos ajudará a refletir, a partir dessa experiência prática, sobre os desafios epistemológicos e metodológicos com os quais nos deparamos ao partilhar o desenvolvimento de nossas pesquisas com crianças.

Uma primeira observação que devo fazer é que a relação de colaboração não foi estabelecida apenas entre eu (adulta) e diversas crianças. Não, a colaboração se deu entre diversos adultos - mestrandos/as, doutorando/as e colegas - e crianças. Creio que esse seja um fator relevante a considerar: a relevância do diálogo intergeracional e interdisciplinar na pesquisa. Sobretudo no campo da antropologia, que ainda conta com uma tradição bastante individualista e autoral na pesquisa, intuo que a possibilidade de realizar investigações colaborativas, entre pesquisadores adultos de diversas áreas e crianças, possa render bons frutos. Assim como Armagnague e Rigoni (2016), procuramos utilizar uma metodologia que pudesse se aproximar do ponto de vista das crianças e jovens, escapando de abordagens frequentemente adultocêntricas, propondo estratégias criativas e colaborativas, por meio de parcerias entre adultos e crianças, visando concretizar situações de coprodução de conhecimento.

Passemos, então, à descrição de alguns resultados práticos da colaboração com crianças e adultos na elaboração do questionário.

\section{COMO PERGUNTAR ÀS CRIANÇAS SOBRE AUTOIDENTIFICAÇÃO?}

Dispor de dados sobre a identificação/autoidentificação das crianças é uma premissa de pesquisas que visem análises 
pautadas na interseccionalidade, ou seja, que cruzem os diferentes marcadores identitários (gênero, raça, classe, idade, etc). Foi nesta perspectiva que experimentei inserir a seguinte pergunta:

- Como você se considera? (Opções de resposta: branca, negra, parda, indígena, amarela, outra cor - qual? não sei).

Ao enviar o questionário para Joana, minha orientanda no Programa de Pós-Graduação em Performances Culturais (PPGPC) da UFG, e sua filha Naomi, de 6 anos, surgiram as primeiras problematizações. Em primeiro lugar, Joana questionou o porquê de a cor "branca" frequentemente ser apresentada como primeira opção (o que já a situaria em uma hierarquia de importância em relação às demais) e depois relatou que, inicialmente, Naomi nem entendeu o teor da pergunta. Foi apenas depois de lhe explicar as diferenças entre uma cor/etnia e outra que Naomi escolheu "parda". A partir desses questionamentos, pensamos juntas em uma pergunta que pudesse revelar as percepções das crianças a respeito de si mesmas, ainda que não as enquadrasse necessariamente em marcadores identitários reconhecidos (embora nem sempre devidamente legitimados) pelos adultos. A pergunta que entrou para o questionário foi:

- Quando você se desenha que cor você usa para pintar a sua pele? (resposta aberta)

Os/as leitores/as conseguem imaginar como foram as respostas? Pois bem, entre "caramelo", "moreno", "bege", "rosa", "marrom meio esverdeado", "meio clara meio escura", "verde", "vermelho" e a espirituosa "não tem cor certa, cada vez pinto de uma cor", também recebemos a seguinte resposta-pergunta: "Rosa claro, por que?". Muito bem, é uma excelente questão que Yunah Mitarashi, menina de 10 anos, nos coloca. A curiosidade dela nos alerta para uma questão relevante: por que queremos saber a "cor" das crianças? De fato, como Naomi já havia antecipado, essa parece ser uma questão que pode dizer muito mais respeito ao universo e às inquietações do mundo dos adultos. Por este motivo as cores citadas nas respostas, em muitos casos, foram cores possíveis, não aquelas refletidas em um espelho. Pois esse "espelho" que surge a partir de uma certa idade 
frequentemente é o outro, o/a colega de escola, o/a amigo/a do prédio que te identifica, te classifica, te inclui ou exclui. Nós, adultos, precisamos refletir sobre essas classificações e, quiçá, expandi-las, aprofundá-las e problematizá-las com o auxílio das crianças.

Nesta pergunta, penso que as respostas informaram menos sobre os marcadores identitários das crianças e mais sobre seus conhecimentos acerca dos pigmentos e respectivas misturas ("Azul escuro, preto e um pouquinho de branco", "mesclo o salmão com o marrom"), sobre padrões de representação em aulas de artes, em contraste com suas capacidades criativas ("não tem cor certa, cada vez pinto de uma cor") além de, e não menos importante, suas inquietações. Parece-me que aqui nos deparamos com uma das dificuldades epistemológicas apontadas por Soares, Sarmento e Tomás, acima: como conciliar nossas demandas de investigação com aquelas das crianças? Bem, alertei no início que esse seria um artigo sobre perguntas. Passemos à próxima.

Como perguntar às crianças sobre gênero?

Algo semelhante ao que foi relatado em relação ao marcador étnico ocorreu com a questão do gênero. A pergunta da primeira versão do questionário era a mais protocolar possível:

- Qual é seu gênero? (Opções de resposta: menina, menino, não sei).

Jonielson, também meu orientando no PPGPC, experimentou compartilhar o questionário com seus filhos Alice, de 5 anos, e Heitor, de 3. Evidentemente, como as perguntas eram pouco significativas para sua faixa etária, Heitor logo se desinteressou, mas Alice se divertiu, sobretudo com as questões que versavam sobre as suas preferências. O pai relatou que para ela o questionário funcionou como um jogo, que inclusive foi expandido a seu pedido - depois de concluírem as respostas, ambos ficaram inventando outras perguntas. Tanto Alice quanto Naomi demonstraram mais interesse por perguntas como "Qual o seu personagem preferido?", "Qual sua cor preferida?", "Você tem ou gostaria de ter um animal de estimação?" e foi a partir do diálogo com elas que na versão final do questionário decidimos 
combinar perguntas mais "técnicas", como as que envolviam auto identificação, moradia, emprego dos responsáveis, etc., com aquelas que versavam sobre suas preferências pessoais e abriam possibilidade para fabulação, tais como "Se você tivesse um superpoder, qual seria?".

Mas voltemos à questão do gênero: para Alice, a pergunta teve de ser adaptada e completada com algumas explicações, pois ela ainda não dispunha do vocabulário específico sobre o tema. Quando Jonielson apontou esse aspecto, que poderia gerar dificuldade de resposta também para outras crianças, mesmo de idade mais avançada, resolvemos alterar a pergunta para:

- Você é... (menina, menino, não sei, outros).

Fizemos questão de ampliar as opções de respostas, contemplando também "outros". Nesta questão recebemos as seguintes respostas: 67 meninas, 49 meninos e 1 gay e não houve questionamentos explícitos por parte de nenhuma criança. $\mathrm{O}$ questionamento, neste caso, foi meu: refletindo sobre a questão, penso que relegar a "outros" todas as possibilidades de identificação em termos de gênero e sexualidade já estabelece uma desigualdade, uma maneira de distinção. É como se aceitássemos que há categorias definidas e aceitas (menina, menino) e há os "outros".

A discussão específica sobre as identidades étnico-racial e de gênero não é o foco deste artigo e há importantes pesquisas sendo realizadas neste sentido (BUSS-SIMÃO, 2013; CARDOSO, 2018; MARCHI, 2011; MOTTA e PAULA, 2019; PONTE, 2019; PRETTO e LAGO, 2013; SILVA, 2015; SOUZA, 2006, entre tantos outros), mas penso que, em todo o caso, devemos aprimorar o diálogo com as crianças, mantendo contínuo questionamento a respeito de nossas formas de definir e compreender os marcadores sociais da diferença. 


\section{O QUE PERGUNTAR ÀS CRIANÇAS SOBRE A PANDEMIA DE COVID-19 E ALGUMAS RES- POSTAS-PERGUNTAS DAS CRIANÇAS}

Além de Naomi e Alice, Luzia, de 6 anos, filha de Maria, minha orientanda no Programa de Pós-Graduação em Artes Cênicas (PPGCEN) da UnB, também colaborou na elaboração do questionário, sobretudo em relação às perguntas sobre o impacto do isolamento social (ela e sua mãe sugeriram que perguntássemos se as crianças estão sonhando mais e que tipo de sonho) e sobre possíveis soluções para a pandemia (ela já se fazia a pergunta "O que você faria se fosse presidente do mundo inteiro?").

Como essa pesquisa se situa na interface entre a Antropologia e as Artes, procuramos pautar as perguntas sobre a pandemia tanto pela perspectiva das experiências vividas pelas crianças durante o isolamento social quanto pela sua capacidade imaginativa e criativa. Desta forma, foram propostas perguntas tanto sobre o que as crianças sabem sobre o vírus, se tem medo, se conhecem alguém que já teve a doença, se sentem falta da escola, como também "Se o Coronavírus fosse uma pessoa, o que você diria para ele?" ou "Se o Coronavírus fosse um personagem, como ele seria?" (essa pergunta oferecia a possibilidade de inclusão de um desenho, como o que podemos ver a seguir). 


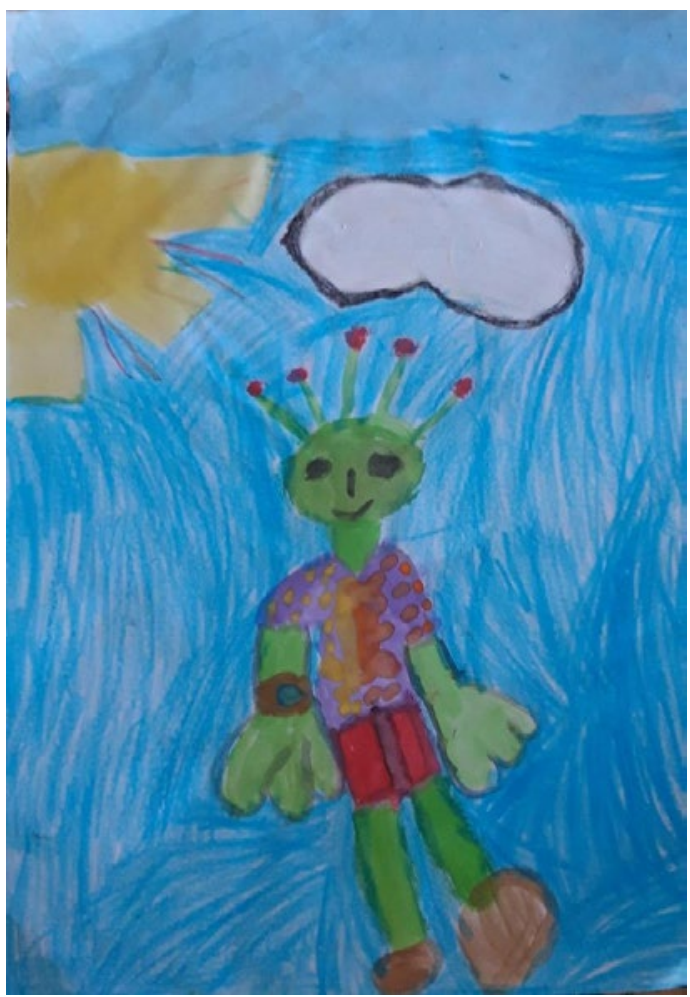

Figura 01: Desenho feito por Azul, de 7 anos - Lisboa/Portugal (Que responde assim à pergunta: "Vou mandar um desenho") Fonte: arquivo da autora 


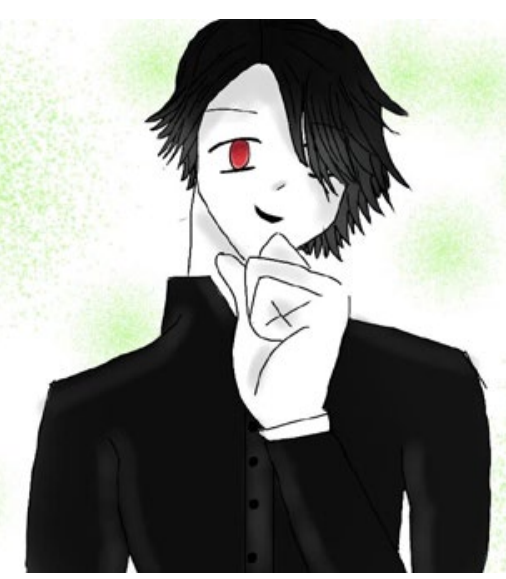

Figura 02: Desenho feito por Lara, de 11 anos - Brasília/Brasil (Na resposta à pergunta ela escreve que o coronavírus: "Seria um personagem de anime branco com cabelo preto e olhos vermelhos.")

Fonte: arquivo da autora

A essa última questão a maior parte das crianças respondeu imperativamente: "Sai daqui!", “Maldito!", "Arrume suas malas e vá embora!", "Malvado! Eu queria que você não existisse.", "Eu te odeio vc é um monstro, vc não tem limites!" ou "Sai daqui seu merda! (Desculpa)". Outros foram bastante pacíficos ou didáticos: "Que os seus guias te mandem pro caminho certo", "Pra ele parar de nos distanciar de quem nós mais amamos e parar de ser tão mal", "Eu diria educadamente para ele entrar em um foguete e se mandar da Terra". E corroborando com o argumento que estamos desenvolvendo aqui, pudemos encontrar também algumas respostas elaboradas de forma interrogativa: "Você tem noção do que você fez?"; "Por que você é tão mau?", "Por que que você não vai infectar as pessoas que estão na lua?". É interessante perceber que são perguntas acusatórias, que demonstram a compreensão que as crianças têm da gravidade da situação. Uma resposta-pergunta, entretanto, adensa mais a reflexão, levando-a para um nível existencial: “Por que, só 
por que?" (Raíssa, de 11 anos). Poderia ser Neruda, no Livro das Perguntas, a se indagar: "Que vim fazer neste planeta? A quem dirijo esta pergunta?" (NERUDA, 2004)

$\mathrm{Na}$ impossibilidade de analisar o questionário na íntegra, até porque não é este o objetivo deste texto, trago ainda mais duas questões que receberam respostas-perguntas por parte das crianças.

Situada após outras questões sobre o contexto escolar atual, a questão 46 desafiava as crianças a um exercício propositivo em relação às novas práticas educacionais: "Como você acha que poderiam ser as aulas durante a pandemia?" Algumas usaram a imaginação combinando tecnologia, prevenção e afetos: “Em um computador que desse para colocar a mão dentro dele a abraçar as pessoas do outro lado", "Colocar plástico filme na escola inteira e ainda passar álcool em gel na escola inteira também e todo mundo ir de máscara", "Imaginava que seria legal se todo mundo fosse para a sala dentro de um quadrado e que a professora falasse e a gente ficasse dentro da sala com aquelas roupas de astronauta, iria ser engraçado.", "Aulas com câmeras e microfones bons, que não deixem o som chiando. Aula divertidas (põe efeitos na imagem do rosto do professor)". Outras demonstraram sentir grande falta das aulas presenciais: "Na escola porque é o único jeito legal”, "Poderia ser na Escola e usar máscara e álcool para se proteger", "Poderia ser na escola, cada aluno com horário marcado. Cinco, dez alunos para cada aula", "Não sei, gosto da escola normal". E várias se mostraram céticas: "Não ter aula e depois da pandemia repetir de ano", "Poderiam ser boas.", "Inexistentes". Uma criança deu uma resposta-pergunta: "Tem que ter aula?" Podemos pensar que esse questionamento é direcionado não apenas à pesquisadora, mas a todos os adultos. Como alerta Priscila Alderson:

As crianças podem ter menos a perder e mais a ganhar, ao fazerem perguntas radicais como: Por que temos reuniões escolares? Os adultos, em compensação, podem se sentir ameaçados por pesquisas, pois podem questionar criticamente seus conhecimentos, autoridade ou conveniência. (ALDERSON, 2005, p. 426) 
Ao problematizar a pergunta feita no questionário, a criança critica a própria formulação dessa e oferece outras opções ao processo, recusando-se a atender a uma demanda que, para ela, é claramente adulta: para que vou imaginar outros formatos de aula se acho que o melhor, nesse momento, seria nem termos aula?

Como disse anteriormente, procurei valorizar, no questionário, a capacidade imaginativa, criativa e de fabulação das crianças em relação à Covid-19 e suas novas dinâmicas de vida neste período de isolamento social. A dissertação de mestrado de Paula Desgualdo, intitulada "Quando a gente podia sair de casa": A cidade na voz das crianças em período de distanciamento social" (DESGUALDO, 2020), recentemente defendida, vai nesta mesma linha, ao salientar o poder do faz-de-conta no encaminhamento metodológico da pesquisa, valorizando a importância do envolvimento do adulto-pesquisador na brincadeira imaginativa com a criança.

Evidentemente temos que ter cuidado para tentar estabelecer o equilíbrio entre, por um lado, olhar para as crianças como agentes ativos e criativos no mundo e, por outro, manter a atenção para as situações de vulnerabilidade a que elas são expostas, sobretudo em contextos de crise sanitária (que no caso brasileiro é agravada pela crise política) como o que estamos vivendo.

Tenho acompanhado os debates na imprensa e em grupos de pesquisa sobre infâncias, que têm demonstrado preocupação com o agravamento da situação de vulnerabilidade das crianças neste período de pandemia. O ProChild CoLAB, por exemplo, um laboratório colaborativo português que se dedica ao combate à pobreza e exclusão social na infância, respondeu rapidamente a essa demanda disponibilizando material interativo, direcionado às crianças, às famílias e aos profissionais, com recursos que visam auxiliar na manutenção da saúde e do bem-estar das crianças e de suas famílias, tanto no nível emocional quanto social, durante a pandemia de Covid-19.

Também o grupo composto pelos espanhóis Marta Martínez Muñoz, Iván Rodríguez Pascual e Gabriela Velásquez Crespo, 
defendendo a necessidade de uma "sociologia de urgência", sem perder o rigor metodológico, lançou a pesquisa "Infância Confinada". Ao longo de duas semanas, entre o final de março e o início de abril, crianças de 10 a 14 anos de idade foram convidadas a responder a um questionário, para que pudessem compartiIhar como estão vivenciando, pensando e sentindo os impactos da pandemia de Covid-19 e das consequentes medidas de isolamento social em suas vidas. O projeto tem sido replicado em outros países e no Brasil o Grupo de Pesquisa Sujeitos, Território e Construção do Conhecimento (GPS), ligado à Faculdade de Educação da UnB e liderado por Maria Lídia Bueno Fernandes, realizou pesquisa semelhante com crianças do Distrito Federal, durante os meses de julho e agosto, e contou, assim como o questionário espanhol, como mais de 400 respondentes. Neste momento o Grupo realiza a análise das respostas e começa a apresentar os primeiros resultados em webinários.

O Grupo Niñez Plural, sediado na Universidade de Buenos Aires, também vem se ocupando de pensar a questão da infância diante da pandemia, de como esta expõe e recrudesce os problemas e violências que muitas vezes afetam as crianças e de como, justamente por isso, devemos estar atentos para garantir a escuta de suas vozes:

[...] consideramos que deberían multiplicarse los esfuerzos para recuperarlas. A su vez, en este contexto pandémico, la convivencia permanente con personas adultas -atravesadas por los mandatos patriarcales y adultistas - agudiza la violencia producto de la angustia propia de la extrema incertidumbre en que se vive, que se descarga sobre mujeres, disidencias y niñxs. (NIÑEZ PLURAL, 2020, s/p)

Reflexo de pesquisas como as mencionadas parece ser o fato de que a imprensa, neste contexto pandêmico também esteja se dedicando mais à escuta das crianças. No entanto, é possível constatar que lhes é destinado, talvez exacerbadamente, o papel de "vítimas". Como coloquei acima, reconheço que as crianças estejam mais vulneráveis à violência doméstica, carências ou distúrbios alimentares, alterações psíquicas, entre ou- 
tras consequências do isolamento social, e é fundamental que nos mantenhamos atentos para que elas possam ter assegurados mecanismos de proteção e cuidado. Considero, porém, que também seja importante poder enxergar as crianças como seres que não apenas respondem às demandas dos adultos, mas que têm suas próprias percepções do mundo, bem como significativas propostas para melhorá-lo e/ou para lidar com a pandemia.

O site Caraminholas de Meninas, por exemplo, foi organizado por um grupo de quatro amigas de cerca de 10 anos de idade, moradoras de Brasília, que por meio de histórias, podcasts, curtas, poesia e tirinhas pretendem tornar menos solitário esse período de isolamento que as crianças estão vivendo. Elas explicam: "Como crianças, também nos sentimos solitárias, estamos com medo e estamos com saudade de ver outras crianças, nossos amigos e avós. Temos muita vontade de conviver e de voltar a abraçar."

Do lado dos adultos, o recente artigo de Vanessa Paula Ponte e Fabrício Neves, "Vírus, telas e crianças: entrelaçamentos em época de pandemia" (2020), oferece uma bela análise de vídeos produzidos por crianças com tecnologias caseiras, tais como celulares e tablets, nos quais elas partilham seus pontos de vista sobre a pandemia de Covid-19 em redes sociais e plataformas públicas da internet. Para além de valorizarem o protagonismo das crianças na produção audiovisual, os autores reconhecem a diversidade das infâncias no uso das tecnologias e assinalam o contexto de grande desigualdade no acesso à internet em nosso país.

Conforme dados da pesquisa TIC Kids Online Brasil, em tempos de ensino remoto, 4,8 milhões de crianças e adolescentes, entre 9 e 17 anos, vivem em casas sem acesso à internet. A exclusão marca profundamente aqueles que vivem em áreas rurais (25\%), nas regiões Norte e Nordeste (21\%) e entre os domicílios das classes D e E (20\%). Por outro lado, a referida pesquisa chama atenção para o uso intensivo da internet por crianças e jovens brasileiros: são 24,3 milhões de usuários entre 9 e 17 anos. (PONTE; NEVES, 2020, p. 89) 
É necessário compreender esse contexto para refletir sobre o perfil socioeconômico das crianças que responderam o questionário e, consequentemente, sobre quem são as crianças que estão sendo ouvidas nesse tipo de pesquisa. Como já foi dito, neste artigo não temos a pretensão de fazer uma análise da totalidade do questionário e de suas respectivas respostas, mas é possível apontar que 1,7\% das crianças que responderam vivem em casas com 1 quarto, 23,7\% vivem em casa com 2 quartos e $57,2 \%$ em casas com 3 quartos, ou seja, podemos supor que a maioria dos respondentes sejam crianças de classe média. Também não se pode desconsiderar o fato de que, embora haja respondentes de todo o país, um percentual significativo reside na região Sul, no Sudeste e no Distrito Federal, o que confirma os dados levantados pela TIC Kids Online Brasil, descritos acima. É importante ter clareza desses aspectos para que não alimentemos falsas expectativas em relação ao alcance de nossas pesquisas, o que, penso, de forma alguma as invalida.

\section{ABRINDO E FECHANDO - O VAI-E-VEM DAS PERGUNTAS}

Ciente de que, apesar das colaborações dadas por Nina, Naomi, Alice e Luzia, o questionário ainda poderia ser bastante aprimorado no diálogo com as próprias crianças, inseri uma última pergunta que possibilitasse a elas justamente se manifestarem e proporem novas questões. A pergunta 52 ficou assim: "Tem alguma coisa que você queira contar que eu não perguntei? Você quer sugerir alguma pergunta?" Para mim, durante o processo de elaboração do questionário estava claro que este deveria refletir as demandas e reflexões das crianças e não somente dos adultos. Embora naquele momento eu ainda não estivesse priorizando o debate sobre a importância de "fazer perguntas" como forma de as crianças se relacionarem com o mundo (e, mais especificamente, com os adultos), esta última questão possivelmente tenha sido a que melhor reflete 
esse aspecto. Nas respostas-perguntas das crianças podemos encontrar inquietações, desejos, posicionamentos éticos e políticos. Vejamos algumas perguntas que elas nos propuseram: "Qual vai ser a primeira coisa que você vai fazer quando o coronavírus acabar?", "O isolamento social está sendo bom, ruim ou mais ou menos?", "O que você acha que o governo deveria fazer para acabar com essa pandemia?", "O que eu faria se eu fosse o coronavírus?", "O que você faria se não houvesse quarentena?", "O que eu faria se tivesse coronavírus?", "Por que nosso planeta inteiro é quente e o vírus é frio?" Imagino que para cada uma dessas perguntas as crianças que as fizeram tivessem suas próprias respostas, que possivelmente gerassem novas perguntas por parte de outras crianças.

No belo livro "Por uma Pedagogia da Pergunta", Paulo Freire e o chileno Antonio Faundez conversam sobre suas experiências como educadores populares, num diálogo que, como diz Moacir Gadotti na introdução, revela "uma concepção da educação como ato dialógico ao mesmo tempo rigoroso e imaginativo". Neste jogo de perguntas e respostas, Faundez nos brinda com as seguintes palavras:

Acho, então, que é profundamente democrático começar a aprender a perguntar. No ensino esqueceram-se das perguntas, tanto o professor como o aluno esqueceram-nas, e no meu entender todo conhecimento começa pela pergunta. Começa pelo que você, Paulo, chama de curiosidade. Mas a curiosidade é uma pergunta! (FREIRE; FAUNDEZ, 2013, p. 51)

Uma imagem de Vai-e-Vem, um brinquedo que tive na infância, me vem à mente. Pergunta vai, pergunta vem. Talvez devêssemos levar mais isso em conta no momento de fazer pesquisas com as crianças. Compartilhar generosamente nossa curiosidade de pesquisadores com a curiosidade das crianças.

Meu desejo, depois de receber todas essas respostas-perguntas das crianças, foi de lançar um novo questionário que as contemplasse. O que será que elas fariam se fossem o coronavírus? Qual a primeira coisa que elas querem fazer quando o 
coronavírus acabar? O que o governo deveria fazer para acabar com a pandemia?

As respostas-perguntas que compõem a epígrafe do artigo - "Por que as mães ficam nervosas? Quando o corona vai embora? Quem mandou o corona?" - também foram dadas à última pergunta do questionário. Algum/a leitor/a teria as respostas?

\section{REFERÊNCIAS}

ALDERSON, Priscilla. As crianças como pesquisadoras: os efeitos dos direitos de participação sobre a metodologia de pesquisa. Educação e Sociedade. Campinas, v. 26, n. 91, p. 419-442, 2005.

ARMAGNAGUE, Maïtena; RIGONI, Isabelle. Saisir le point de vue de l'enfant. Enquêter sur la participation socioscolaire des élèves migrants. Recherches Qualitatives - Hors-série - n. 20, p. 311329, 2016.

BUSS-SIMÃO, Márcia. Relações sociais de gênero na perspectiva de crianças pequenas na creche. Cadernos de Pesquisa, v. 43, n. 148, p. 176-197, 2013.

CARDOSO, Daniel. Notas sobre a Criança transviada: considerações queerfeministas sobre infâncias. Periódicus - Revista de estudos indisciplinares em gêneros e sexualidades, Salvador, n. 9, v. 1, p. 214-233, 2018.

DESGUALDO, Paula. "Quando a gente podia sair de casa": A cidade na voz das crianças em período de distanciamento social. Dissertação (Mestrado em Educação). Florianópolis, UFSC, 2020.

FREIRE, Paulo, FAUNDEZ, Antonio. Por uma pedagogia da pergunta. Rio de Janeiro: Paz e Terra, 2013.

HARTMANN, Luciana. Interfaces entre a Pedagogia do Teatro e os Estudos da Performance. Educação. Santa Maria/RS, v. 39, p. 515-528, 2014. 
Desafios da diversidade em sala de aula: um estudo sobre performances narrativas de crianças imigrantes. Cadernos Cedes, v. 37, p. 45-64, 2017.

. Vozes em diáspora: como crianças imigrantes contam suas histórias. Revista del Museo de Antropologia, Córdoba/Argentina, v. 11, p. 83-90, 2018.

MARCHI, Rita de Cássia. Gênero, infância e relações de poder: interrogações epistemológicas. Cadernos Pagu, n. 37, p, 387406, 2011.

MILLER, Daniel. Notas sobre a pandemia: como conduzir uma etnografia durante o isolamento social. Disponível em: https:// blogdolabemus.com/2020/05/23/notas-sobre-a-pandemiacomo-conduzir-uma-etnografia-durante-o-isolamento-socialpor-daniel-miller/

MOTTA, Flávia; PAULA, Claudemir de. Questões Raciais para Crianças: resistência e denúncia do não dito. Educação \& Realidade, Porto Alegre, v. 44, n. 2, p. 1-18, 2019.

NERUDA, Pablo. Livro das perguntas. Tradução de Olga Savary. Porto Alegre: L\&PM, 2004.

NIÑEZ PLURAL. Las infancias ante la pandemia: reflexiones y desafíos desde las ciencias sociales. Marcha - una mirada popular y feminista de la Argentina y el mundo, publicado em 17.05.2020. Disponível em: https://www.marcha.org.ar/lasinfancias-ante-la-pandemia-reflexiones-y-desafios-desde-lasciencias-sociales/

NIÑEZ PLURAL. Niñez, alteridad y cuidado: reflexiones para un campo en construcción. DesIdades, n. 25, año 7, p. 48-58, 2019.

PIRES, Flávia, "Ser adulta e pesquisar crianças". Revista de 
Antropologia, São Paulo, v. 50, n. 1, pp. 225-70, 2007.

PONTE, Vanessa Paula. “Embelezamento, mídia e construção do corpo em narrativas de crianças: Nuances de uma etnografia nos salões". RUNA - Archivo para las Ciencias del Hombre, Buenos Aires, p. 131-48, v. 40, 2019.

PONTE, Vanessa Paula; NEVES, Fabrício. Vírus, telas e crianças: entrelaçamentos em época de pandemia. Simbiótica, Edição Especial, vol.7, n.1, p. 87-106, 2020.

PRETTO, Zuleica; LAGO, Mara C. de S. Reflexões sobre infância e gênero a partir de publicações em revistas feministas brasileiras. Revista Ártemis, v. XV, n. 1, p. 56-71, 2013.

RUBINSTEIN, Edith. A pergunta no processo de ensinoaprendizagem. Revista Psicopedagogia, v. 36, n. 111, p. 317-31, 2019.

SILVA, Petronilha B. G. Crianças negras entre a assimilação e a negritude. Revista Eletrônica de Educação, v. 9, n. 2, p. 161-187, 2015.

SOARES, Natália Fernandes; SARMENTO, Manuel Jacinto; TOMÁS, Catarina. Investigação da infância e crianças como investigadoras: metodologias participativas dos Mundos sociais das crianças. Nuances: estudos sobre educação - ano XI, v. 12, n. 13, p. 49-64, 2005.

SOUZA, Érica Renata de. Marcadores sociais da diferença e infância: relações de poder no contexto escolar. Cadernos Pagu, n. 26, p.169-199, 2006. 